\title{
Interfaces in ordered intermetallics
}

\author{
J B SINGH*, M SUNDARARAMAN and S BANERJEE \\ Metallurgy Division, Bhabha Atomic Research Centre, Bombay 400085, India
}

\begin{abstract}
In this paper, we have examined different types of interfaces that occur between orientational/translational variants generated during the ordering process. This has been illustrated citing examples of ordering of the $\mathrm{FCC}$ structure into $\mathrm{DO}_{2}, \mathrm{Dl}_{\mathrm{a}}$ and $\mathrm{Pt}_{2} \mathrm{Mo}$ type structures in some nickel base alloys. Microstructures consisting of more than one ordered structure have also been investigated. Superlattice domains of $\mathrm{DO}_{22}$ and $\mathrm{Pt}_{2} \mathrm{Mo}$ type structures have also been found to coexist in a microscopic scale of mixing in $\mathrm{Ni}-\mathrm{V}$ alloys while mixed domains of $\mathrm{Dl}_{\mathrm{a}}$ and $\mathrm{Pt}_{2} \mathrm{Mo}$ type structures on a much finer scale have been observed in $\mathrm{Ni}-\mathrm{Mo}$ alloys. The formation of different variants (rotational and translational) of ordered structure(s) from the disordered lattice has been explained on the basis of group theoretical and symmetry considerations.
\end{abstract}

Keywords. Ordering; intermetallics; interfaces; $\mathrm{DO}_{22}, \mathrm{Dl}_{\mathrm{a}}$, and $\mathrm{Pt}_{2} \mathrm{Mo}$ structures.

\section{Introduction}

Ordered intermetallics are receiving renewed attention as structural materials for high temperature applications (Liu 1993). The ordering of an alloy from the disordered state below $T_{c}$, the critical temperature for ordering, leads to the formation of a substructure consisting of translational and orientational variants as ordering is initiated independently at different parts of the disordered crystal. If different orientations of the ordered lattice are generated in the disordered matrix, then the substructure consists of orientational variants or transformation twins with special interfaces between them. However, if only one orientational variant nucleates in the disordered lattice then antiphase domain boundaries are created. These interfaces often act as barriers to dislocation propagation across them and hence influence the mechanical properties of an alloy. Transmission electron microscopy has been employed as the main experimental tool to identify and characterize the different types of domain boundaries and also to study the mechanism of dislocation propagation across these boundaries (Ruedl et al 1968).

An elegant group theoretical formulation has been developed by earlier researchers to determine the number of variants formed and also the nature of the interfaces between them (both homo- and hetero-interfaces) during an ordering transition (Tendeloo and Amelinckx 1974; Cahn and Kalonji 1982; Gratias and Portier 1982). This aspect will be illustrated with the help of examples of the ordering of the FCC structure to $\mathrm{DO}_{22}, \mathrm{Dl}_{\mathrm{a}}$ and $\mathrm{Pt}_{2} \mathrm{Mo}$ structures in the $\mathrm{Ni}-\mathrm{V}$ and the $\mathrm{Ni}-\mathrm{Mo}$ alloy systems. The generation of different variants of more than one ordered structure from the disordered lattice has also been investigated in these systems and the observed results have been rationalized on the basis of group theoretical and symmetry considerations.

\footnotetext{
*Author for correspondence
} 


\section{Symmetry considerations}

A detailed consideration of the group theoretical formulation to determine the number of variants that occur during ordering is beyond the scope of this paper and can be obtained in the literature (Tendeloo and Amelinckx 1974; Cahn and Kalonji 1982; Gratias and Portier 1982). Only a brief account of the methodology to be followed is described here.

If $d_{1}$ and $o_{1}$ represent the orders of the group of symmetry operations of the disordered parent lattice, $D$, and the ordered lattice, $O$, respectively, $(O \subset D)$, then the number of orientational variants of the ordered lattice formed from the disordered structure is given by the ratio of the order of the group $\mathrm{D}$ to the order of the group $\mathrm{O}$ of the ordered lattice. i.e. by $d_{1} / o_{1}$. The order of a group is nothing but the number of symmetry operations of the group. The number and the type of interfaces between different rotational variants have been shown to be equal to the number of classes of the variant generating group other than the identity operation (Tendeloo and Amelinckx 1974). The translational symmetry lost during ordering appears as antiphase domain boundaries. The number of translational variants, $t$, is given by the ratio $V_{0} / V_{\mathrm{d}}$, where $V_{0}$ and $V_{\mathrm{d}}$ represent the volumes of the primitive unit cell of the ordered and the disordered structures respectively. For nonprimitive unit cells, the multiplicity of the respective structures should be taken into account. The number of antiphase boundaries between the different translational variants is given by $t-1$. The number of translational variants can also be determined from the $|M|$, where $M$ represents the transformation matrix from the primitive base of the disordered structure to the primitive base of the ordered structure.

Cahn and Kalonji (1982) developed a formalism to find out the number of variants of one ordered structure nucleating within another ordered structure from symmetry considerations. This involves finding out the intersection group, $\mathrm{H}$, which contains elements common to the ordered structures, $\mathrm{O}_{1}$ and $\mathrm{O}_{2}$. A prior knowledge of the orientation relationship between the structures is necessary. The intersection group can be found out by extending the lattices past the interface to see if any of the symmetry elements represents the intersection group, $\mathrm{H}$. The number of variants of the ordered phase $\mathrm{O}_{2}$ nucleating in the ordered phase $\mathrm{O}_{1}$ is nothing but the ratio of the order of $\mathrm{O}_{1}$ to the order of $\mathrm{H}$. Similarly, the number of variants of $\mathrm{O}_{1}$ which can nucleate within $\mathrm{O}_{2}$ is equal to the ratio of the order of $\mathrm{O}_{2}$ to the order of $\mathrm{H}$. The success of this formalism is illustrated by taking the examples of

Table 1. Number of rotational and translational variants of ordered structures derived from disordered fcc ( $m 3 m$ ) lattice of order 48 .

\begin{tabular}{lccc}
\hline $\begin{array}{l}\text { Crystal structure } \\
\text { space group symmetry }\end{array}$ & $\mathrm{Dl}_{\mathrm{a}}(\mathrm{I} / \mathrm{m})$ & $\mathrm{DO}_{22}(\mathrm{I} / \mathrm{mmm})$ & $\mathrm{Pt}_{2} \mathrm{Mo}(\mathrm{Immm})$ \\
\hline $\begin{array}{l}\text { Order of group } \\
\text { No. of rotational variants }\end{array}$ & 8 & 16 & 8 \\
$\begin{array}{l}\text { No. of classes of elements other } \\
\text { than identity }\end{array}$ & 6 & 3 & 6 \\
$\begin{array}{l}\text { Nature of rotational (or twin) } \\
\text { boundary }\end{array}$ & $\begin{array}{c}\text { Antiparallel } \\
\text { Perpendicular }\end{array}$ & Perpendicular & $\begin{array}{c}\text { Parallel } \\
\text { Perpendicular }\end{array}$ \\
No. of translational variants & 5 & 4 & 3 \\
No. of anti-phase boundaries & 4 & 3 & 2 \\
\hline
\end{tabular}


ordering from the $\mathrm{FCC}$ to the $\mathrm{DO}_{22}+\mathrm{Pt}_{2} \mathrm{Mo}$ and from the $\mathrm{FCC}$ to the $\mathrm{Dl}_{\mathrm{a}}+\mathrm{Pt}_{2} \mathrm{Mo}$ structures.

\section{Nucleation of one ordered structure from the disordered structure}

Following the methodology mentioned in the last section and described in detail elsewhere (Tendeloo and Amelinckx 1974; Cahn and Kalonji 1982; Gratias and Portier 1982), the number of translational and rotational variants formed and the interfaces between them have been determined for the ordering of the FCC structure $(F(m 3 m))$ into the $\mathrm{Dl}_{\mathrm{a}}(I 4 / m)$, the $\mathrm{DO}_{22}(14 / \mathrm{mmm})$ and the $\mathrm{Pt}_{2} \mathrm{Mo}(\mathrm{Immm})$ structures respectively, and are given in table $\mathrm{l}$.

\section{1 $F C C \rightarrow D 1_{\mathrm{a}}$ ordering}

The structure of fully ordered $\mathrm{Ni}_{4} \mathrm{Mo}$ is $\mathrm{BCT}(I 4 / \mathrm{m})$ with a $c / a$ ratio of 0.986 and with the $c$-axis parallel to one of the cube axes of the disordered FCC lattice and the $a$-axes along
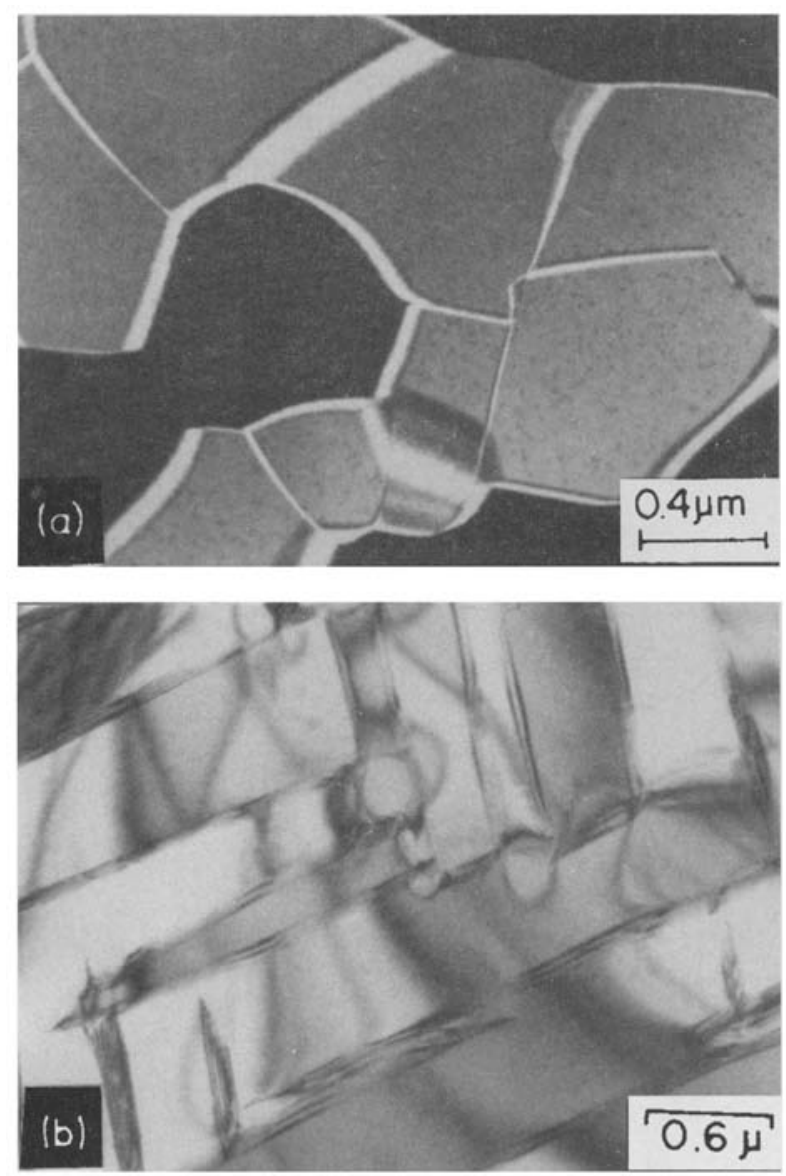

Figure 1. Bright field micrograph in LRO $\mathrm{N}_{4} \mathrm{Mo}$ alloy showing (a) antiparallel twin boundaries which are curved and (b) perpendicular domain boundaries which are highly planar. 
appropriate $\langle 120\rangle$ directions (Ruedl et al 1968). Six orientational variants of $\mathrm{Ni}_{4} \mathrm{Mo}$ form in the disordered structure (see table 1) and they have been experimentally identified in a TEM investigation by Ruedl et al (1968). They orient amongst themselves either in antiparallel ( $c$-axes in antiparallel orientation in adjacent domains) or in perpendicular ( $c$-axes perpendicular to each other) twin configurations (table 1). The basic lattice can be shown to be continuous across the interface in the antiparallel twin orientation and to be discontinuous in the perpendicular twin orientation (Ruedl et al 1968). This is reflected in the nature of the interface: it is isotropic for antiparallel orientation and highly anisotropic for perpendicular orientation. Typical examples of these boundaries in the $\mathrm{Ni}_{4} \mathrm{Mo}$ alloy are shown in figure 1 . The $1 / 2\langle 110\rangle$ type translational vectors lost during the ordering reaction appear as antiphase boundaries. As shown in table 1, five translational variants are possible with four types of APBs between them (Ruedl et al 1968).
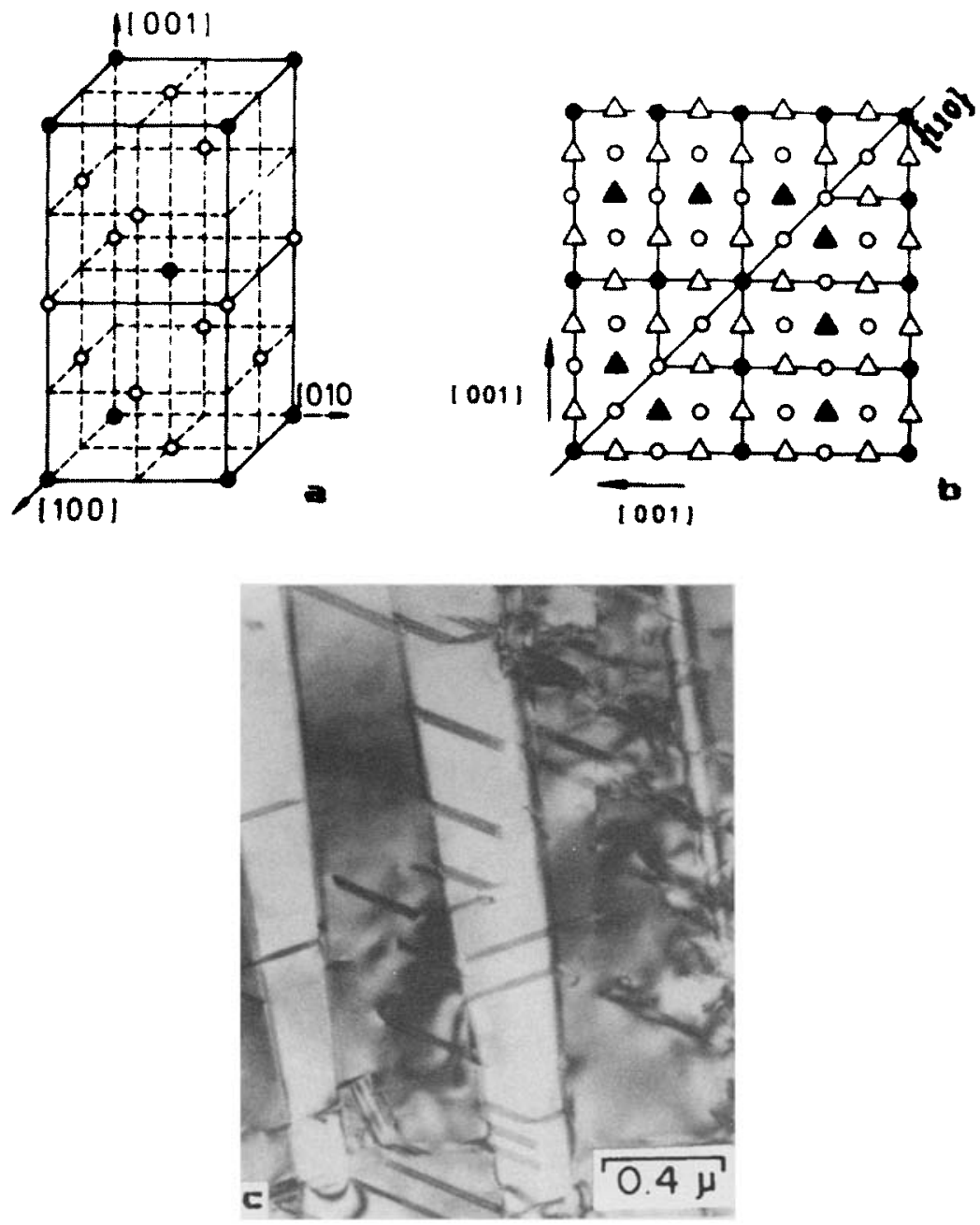

Figure 2. (a) Unit cell of $\mathrm{DO}_{22}$ structure, (b) [001] projection of perpendicular twins and (c) lenticular shaped twin lamellae of $\mathrm{Ni}_{3} \mathrm{~V}$ variants; $\{110\}$ is the twin plane. 


\section{2 $\mathrm{FCC} \rightarrow \mathrm{DO}_{22}$ ordering}

The formation of the ordered $\mathrm{Ni}_{3} \mathrm{~V}\left(\mathrm{DO}_{22}\right.$ structure) phase with a $c / a$ ratio of 2.036 below the transition temperature of $1045^{\circ} \mathrm{C}$ from the disordered FCC phase is a typical example of FCC to $\mathrm{DO}_{22}$ ordering (Tanner 1968). Since the $c$-axis of $\mathrm{Ni}_{3} \mathrm{~V}$ can align along any one of the $a$-axes of the $\mathrm{FCC}$ structure, the ordered $\mathrm{Ni}_{3} \mathrm{~V}$ phase can have three mutually orthogonal variants or transformation twins (Tanner 1968) (table 1). Only one type of interface can form between these variants which are perpendicular twins (table 1) with $c$-axes perpendicular to each other in adjacent domains. Because of the tetragonal distortion associated with the $c$-axis, the basic lattice is not continuous across the interface. The domain boundary is highly anisotropic and this is reflected in the interface lying along $\left\{\begin{array}{lll}1 & 1 & 0\end{array}\right\}$ type planes. Depending upon the ageing temperature, different types of microstructures are produced: prism-shaped cells bounded by $\left\{\begin{array}{lll}1 & 1 & 0\end{array}\right\}$ type interface for high undercooling, and parallel lenticular-shaped twin lamellae with perpendicular twin boundaries along

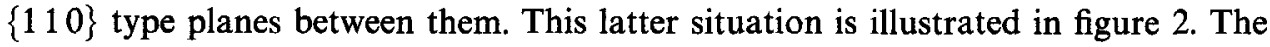
translation vectors of the FCC lattice $(1 / 2\langle 110\rangle$ type), lost during the ordering to the $\mathrm{DO}_{22}$ structure appear as three types of antiphase domain boundaries (table 1). The boundary with the lowest APB energy is frequently observed in samples after prolonged ageing.

\subsection{FCC $\rightarrow \mathrm{Pt}_{2}$ Mo type ordering}

The ordered orthorhombic $\mathrm{Ni}_{2} \mathrm{~V}$ phase (Immm) forms at temperatures below $T_{\mathrm{c}}=920^{\circ} \mathrm{C}$ from a disordered solid solution (Giessen and Grant 1965). The $c^{\prime}$-axis can be aligned along any one of the $a$-axes of the FCC structure and the $a^{\prime}$ and the $b^{\prime}$ axes along appropriate $\langle 110\rangle$ directions (figure $3 \mathrm{a}$ ). Six independent variants of $\mathrm{Ni}_{2} \mathrm{~V}$ form in the FCC structure (table 1) (Tanner 1972). These six variants are transformation twins of two types-parallel (where the different variants have the same $c^{\prime}$ axis while the $a^{\prime}$ and the $b^{\prime}$ axes are rotated by $90^{\circ}$ ) and perpendicular ( $c^{\prime}$ axes are mutually perpendicular) (figures $3 \mathbf{b}$ and $c$ ). Since the basic lattice is not continuous across the interface, both the types of interfaces are anisotropic and hence they occupy a specific plane as shown in the figure. Three translational variants and two types of APBs form in this structure (table 1) (Tanner 1972).

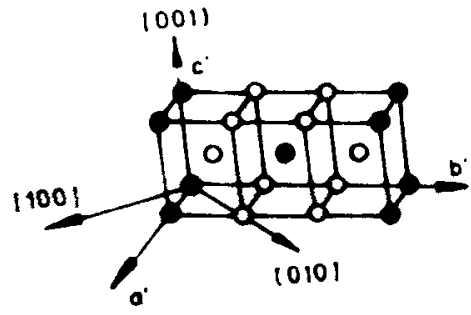

(a)



(b)

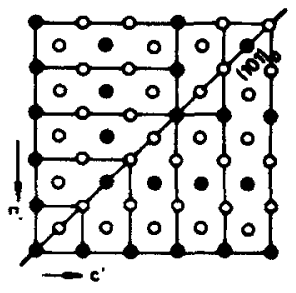

(c)

Figure 3. (a) Unit cell of $\mathrm{Pt}_{2} \mathrm{Mo}$ structure; [00 1] projection showing (b) parallel twins and (c) perpendicular twins. Twin boundary planes are marked in the figure. 


\section{Nucleation of more than one ordered structure from disordered structure}

\section{1 $\mathrm{FCC} \rightarrow \mathrm{DO}_{22}+\mathrm{Pt}_{2} \mathrm{Mo}$ type ordering}

$\mathrm{DO}_{22}\left(\mathrm{Ni}_{3} \mathrm{~V}\right)$ and $\mathrm{Pt}_{2} \mathrm{Mo}\left(\mathrm{Ni}_{2} \mathrm{~V}\right)$ phases precipitate from the solid solution (FCC) in the $\mathrm{Ni}-\mathrm{V}$ alloy system in the composition range of $25-33$ at $\% \mathrm{~V}$ with $\{120\}$ type interfaces (Singh et al 1994). When the lattices of $\mathrm{Ni}_{3} \mathrm{~V}$ and $\mathrm{Ni}_{2} \mathrm{~V}$ are extended across an interface of this type, the surviving/superimposing symmetry elements are one two-fold rotation and a mirror perpendicular to it. The point group of the intersection group, therefore, is $2 / m$ of order 4 . The number of variants of the $\mathrm{Pt}_{2} \mathrm{Mo}$ type structure $\left(\mathrm{Ni}_{2} \mathrm{~V}\right)$ that can nucleate in the $\mathrm{DO}_{22}\left(\mathrm{Ni}_{3} \mathrm{~V}\right)$ structure of order 16 can be found out following Cahn and Kalonji's (1982) formalism elucidated earlier to be 4 . On the other hand, the number of


Figure 4. (a) Bright field micrograph of $[010]$ variant of $\mathrm{Ni}_{3} \mathrm{~V}$; (b) and (c) are dark field micrographs of two $\mathrm{Ni}_{2} \mathrm{~V}$ variants. Dark regions marked by arrows in (a) correspond to two more variants of $\mathrm{Ni}_{2} \mathrm{~V}$. 
variants of the $\mathrm{DO}_{22}\left(\mathrm{Ni}_{3} \mathrm{~V}\right)$ structure nucleating within the $\mathrm{Pt}_{2} \mathrm{Mo}$ type structure $\left(\mathrm{Ni}_{2} \mathrm{~V}\right)$ of order 8 is 2 .

Experimental results of investigation on the precipitation of $\mathrm{Ni}_{3} \mathrm{~V}$ and $\mathrm{Ni}_{2} \mathrm{~V}$ phases in the $\mathrm{Ni}-\mathrm{V}$ alloy system have been reported earlier (Singh et al 1994). The microstructure essentially consists of large domains of $\mathrm{Ni}_{3} \mathrm{~V}$, subdivided into parallel lenticular shaped twin lamellae which constitute another transformation variant of this phase (figure 4). $\mathrm{Ni}_{2} \mathrm{~V}$ variants nucleating within each variant of $\mathrm{Ni}_{3} \mathrm{~V}$ can be identified by imaging them using superlattice reflections corresponding to each variant. Four variants of $\mathrm{Ni}_{2} \mathrm{~V}$ phase have been observed within each variant of $\mathrm{Ni}_{3} \mathrm{~V}$ in agreement with the predictions of the group theoretical formalism (table 1). The observed polydomain morphology is attributed to the elastic interaction between the tetragonal and the orthorhombic distortions associated with the ordering process.

\subsection{FCC $\rightarrow D 1_{\mathrm{a}}+\mathrm{Pt}_{2}$ Mo type ordering}

The formation of the $\mathrm{Pt}_{2} \mathrm{Mo}\left(\mathrm{Ni}_{2} \mathrm{Mo}\right)$ and the $\mathrm{Dl}_{\mathbf{2}}\left(\mathrm{Ni}_{4} \mathrm{Mo}\right)$ long-range ordered structures during the initial stages of ordering in binary and ternary $\mathrm{Ni}_{3} \mathrm{Mo}$ based alloys is another example of the nucleation of more than one ordered phase in the disordered lattice. Using the concentration wave approach (Banerjee et al 1989), with $\langle 11 / 20\rangle$ wave vectors in two perpendicular directions, it was shown that the resulting structure is an ordered arrangement of $\mathrm{Dl}_{\mathrm{a}}\left(\mathrm{Ni}_{4} \mathrm{Mo}\right)$ and $\mathrm{Pt}_{2} \mathrm{Mo}\left(\mathrm{Ni}_{2} \mathrm{Mo}\right)$ sub unit cell clusters, each being made up of one molecule of $\mathrm{Ni}_{4} \mathrm{Mo}$ (square shaped) or $\mathrm{Ni}_{2} \mathrm{Mo}$ (diamond shaped) respectively (figure 5). This structure has the average composition of $\mathrm{Ni}_{3} \mathrm{Mo}$ and the internal energy of this cluster seems to be the same as that of $\mathrm{Ni}_{3} \mathrm{Mo}\left(\mathrm{DO}_{\mathrm{a}}-\right.$ the equilibrium structure) (Banerjee et al 1989). Two variants each of $\mathrm{Ni}_{2} \mathrm{Mo}$ and $\mathrm{Ni}_{4} \mathrm{Mo}$ completely fill the two-dimensional projection of the disordered space lattice with $\{120\}$ type interfaces between them. Such a mixture can exist in the sub unit cell cluster size itself. Evidence for the existence of such clusters was obtained from experimental investigations on the initial stages of ordering in $\mathrm{Ni}_{3} \mathrm{Mo}$ alloy (Banerjee et al 1989) and

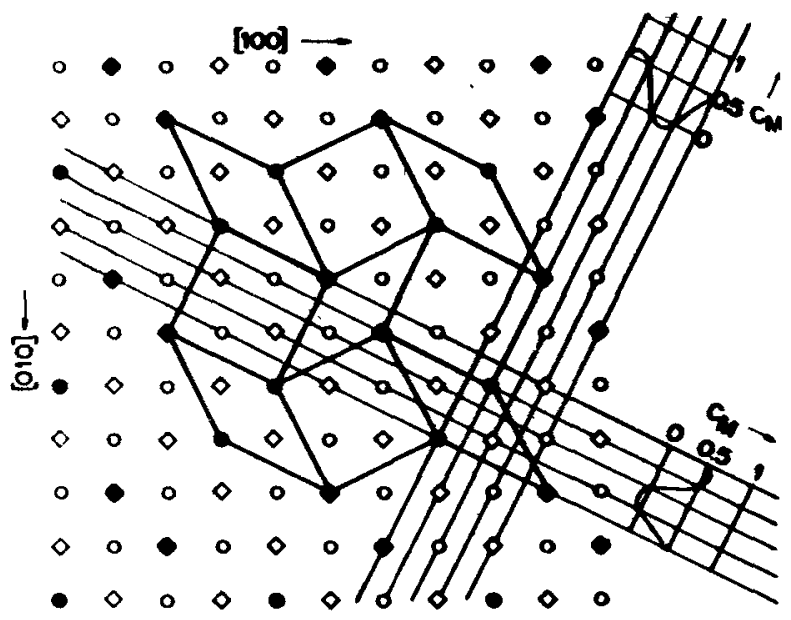

Figure 5. [001] projection showing regular arrangement of sub unit cell clusters of two variants of $\mathrm{Ni}_{2} \mathrm{Mo}$ and two variants of $\mathrm{Ni}_{4} \mathrm{Mo}$ in an alloy having $\mathrm{Ni}_{3} \mathrm{Mo}$ composition. 
was confirmed by the agreement of the results of the computer simulation of diffraction patterns from two dimensional gratings, representing different stages of evolution of order for cluster sizes ranging from 1-4 (Kulkarni et al 1988).

Following the procedure outlined earlier, the point group of the intersection group between $\mathrm{Dl}_{\mathrm{a}}$ and $\mathrm{Pt}_{2} \mathrm{Mo}$ structures is found to be $2 / \mathrm{m}$ of order 4 . The number of $\mathrm{Ni}_{2} \mathrm{Mo}\left(\mathrm{Pt}_{2} \mathrm{Mo}\right.$ type) variants in $\mathrm{Ni}_{4} \mathrm{Mo}\left(\mathrm{Dl}_{\mathrm{a}}\right.$ structure of order 8 ) is 2 . Similarly the number of variants of $\mathrm{Ni}_{4} \mathrm{Mo}\left(\mathrm{Dl}_{\mathrm{a}}\right)$ that can nucleate within each variant of $\mathrm{Ni}_{2} \mathrm{Mo}$ $\left(\mathrm{Pt}_{2} \mathrm{Mo}\right.$ of order 4) is also 2. As described earlier in the context of the evolution of order in the $\mathrm{Ni}_{3} \mathrm{Mo}$ alloy, clusters of two variants of $\mathrm{Ni}_{4} \mathrm{Mo}$ and $\mathrm{Ni}_{2} \mathrm{Mo}$ completely fill the space lattice.

\section{Conclusions}

Group theoretical and symmetry considerations have been used to validate the experimental observations on the precipitation of different variants of an ordered structure from the disordered structure or from another ordered structure in $\mathrm{Ni}-\mathrm{Mo}$ and $\mathrm{Ni}-\mathrm{V}$ alloys.

\section{Acknowledgement}

The authors appreciate the encouragement and support received from Dr C K Gupta, Director, Materials Group, BARC, Bombay.

\section{References}

Banerjee S, Kulkarni U D and Urban K 1989 Acta Metall. 3735

Cahn J W and Kalonji G 1982 Solid-solid phase transformations (Warrendale, USA: Met. Soc. AIME Publications) p. 3

Gratias D and Portier R 1982 J. Phys. Colloque 4315

Giessen B C and Grant N J 1965 J. Less Common Metals 8114

Kulkarni U D, Muralidhar S and Banerjee S 1988 Phys. Status Solidi 2110331

Liu C T 1993 High temperature ordered intermetallics (eds) I Baker et al (Pittsburgh, USA: MRS) 288, p. 3

Ruedl E, Delavignette P and Amelinckx S 1968 Phys. Status Solidi 28305

Singh J B, Sundararaman M and Mukhopadhyay P 1994 Solid-solid phase transformations (eds) W C Johnson et al (Warrendale: TMS) p. 153

Tanner L E 1968 Phys. Status Solidi 30685

Tanner L E 1972 Acta Metall. 201197

Van Tendeloo G and Amelinckx S 1974 Acta Cryst. A30 431 